\title{
Teaching Vocabulary is Bigger than Just Working with a Ten Letter Word
}

\author{
Barba Aldis Patton \\ University of Houston-Victoria, Victoria, TX USA
}

\begin{abstract}
Vocabulary is one of the greatest challenges facing the classroom teacher. This is not a new challenge as it is one which teachers have tried through the years to provide techniques to benefit their students. If a teacher is not able to guide his/her students to have the knowledge or power of words that student will not be able to be successful in today's world. Guiding students to master words specific to a discipline such as math is not as simple as just memorizing.
\end{abstract}

\section{Introduction}

As we are moving from the old one room school houses to the modern and technological age, some things never seem to keep up with the times or go with the flow. The teaching of vocabulary is just one of those things which have been slow to move forward. Maybe a few decades ago, words were thought to only have a single meaning but today it is not the case.

\section{Theoretical Framework}

Words have multi-definitions. The word 'long' can and does have relation to the length of some object however; it is also the name of a tractor used on the farm. (There are also many slang words used to mean the opposite of its true meaning but these will not be included in our discussion.) Students do not master vocabulary by just memorizing a simple definition for a word [1], [2]. This might have been true when things were simpler but today words must be put be in context. Students who are working with a second language, have a low economic background (lack of experiences) are faced with these challenges each and every day. Although students have been expected to earn to use context to gain meanings many students are not able to do this task. Some educators, who are actively in the field such as S. Trowbridge, see this as a lack of experiences while others advocate it as being a development. The fact that the student can't detect meaning from context whatever is the reason faces challenges which are even greater than their peers who are able to use context clues [3].

The teaching of mathematics definitely involves the student being able to do basic computation but there is a huge reading (literacy) factor involved. Research and techniques which are proving to be successful must be addressed if we are to be to continue helping students master the unique lingo or language of each discipline. We must step forward and look beyond teaching vocabulary with flashcards. In this respect we are still thinking vocabulary is just a ten letter word to be memorized just like those flash cards of yester-year [4].

As we look and think about the road to mathematical literacy we must start at the beginning. Mathematical literacy begins with communication and that oral communication begins at birth. Within a few seconds of birth, a new baby is hearing sounds. These sounds all have meaning. As the child grows he/she is able to comprehend the meaning of the sounds. The young child is able to communicate she/he is hunger or desires a drink of water. This early communication is an ordinary language (maybe English or French). [5] This ordinary language is very important, but it is not a formal or academic language which is needed to be more technical or precise in the academic environment. While both types of languages are important to the person, each language has its own place and value. As much as one would like, many times the two differ greatly and in fact one can even create confusion. One would think that a student in the eleventh grade in a typical US school would be very versed in both languages yet the giant question facing the academic world is how we are able to help the student gain literacy in both environments in a relatively short period of time.[6] Using the assumption that each discipline is unique with its own language but recognizing that mathematics and science have many similarities, we find Holliday's finding rather profound and scary when we are attempting to help students gain academic literacy. Holliday [7] found that in chemistry textbooks there are approximately 3000 new words for the student to master in a few months' timeframe. Students who are studying a new language aren't expected to master that many. Patton [8] found that upon an analysis of released state mathematics tests for third, fourth, and fifth grades there were approximately 250 words which needed teacher explanations in order for the student to be fluent to be able to solve the problem. These released state tests generally had a two to four brief sentence situational problem followed by four possible 
responses. Most of the tests had between 40-50 problems. By doing a little simple division, we discover that there were about 4-6 new words in each situational problem. Just a single word that cannot be defined by using context clues will hinder a student to the point that she/he will likely give an incorrect response.

Reading instruction must teach the basics of reading i.e. letter recognition, sounds, phonics, patterns, and spelling but the challenge today is preparing the student for the required reading cognition in the other academic areas as well. Since the general public demands accountability, students must be fluent in many areas. Reading the textbooks is a huge task but in order for students to gain content literacy, they must be able to read, write, talk about the discipline being studied but also apply that which was read [9].

As we venture into reading in the mathematics context, we are in a totally different environment. Yes, we still have many words which remain constant but many now have a different meaning. Now there is the additions to the mix are signs and symbols which replace words and these words are not just common ordinary words. But wait, there is more. Now there are illustrations. When we began to read in kindergarten and first grade, one of the first things we learned was to start at the top left and read the words from left to right, and then read the lines from top to bottom. Illustrations are different. Some are read right to left and it varies with the illustration, others are top to bottom or bottom to top and then still others are read from the middle out [4].

The National Council of Teachers of Mathematics (NCTM) has expressed over and over the importance of students not only knowing how to do mathematical computation, but also their need to know how to use information in the communication of mathematical thoughts [10], [11], [12], [13] (NCTM 1989, 1990, 1991, 2000). In Curriculum and Evaluation Standards for School Mathematics [10], they state: The development of a student's power to use mathematics involves learning the signs, symbols, and terms of mathematics. This is best accomplished in problem-solving situations in which students have an opportunity to read, write, and discuss ideas in which the use of the language of mathematics becomes natural. As students communicate their ideas, they learn to clarify, refine, and consolidate their thinking [14], [15].

During a recent teacher training, it was suggested it is possible that students may have such difficulty comprehending mathematics is the complexity of the sentence structure of the written passages, [16] Basically she believes students today lack a background in English grammar and mathematics syntax. It is not any wonder students do not understand signs and symbols which link mathematical phrases when the student does not really understand what a verb is or how a verb is needed to link a subject with an object. It is no surprise the students don't understand descriptive phrases or even what that phrase modifies. Linville [16] and Shuard \& Rothery [17] advocate the syntax makes reading difficult. The syntax is the words are put together to form sentences, phrases and clauses. In reading the textbooks for classes such as the language arts, the syntax is generally subject then verb but in math that is a different situation. While we might ask what is $3+4=$ ? but we also might ask $3+?=7$ or $4+3=$ ? In mathematics we strive for the student to be able to apply the basic facts in numerous problem solving situations

Researchers have long noted that mathematics vocabulary in mathematics text can be extremely challenging for all readers even the talented or gifted students. [8] Vocabulary does not seem to be a given with any group of students. The work of [18] [19] and later with Pierce and Fontaine [20] expose the fact which had been hidden for years that vocabulary does affect achievement in arithmetic predominantly in problem solving situations. Mathematics of the 21st century is no longer just reciting facts but solving real-life situational problems. Released state tests in almost every state in the United States disclose this [21], [22], [23], [24,] [25] "Reading comprehension and arithmetic achievement tend to be positively related. Almost without exception instruction in vocabulary and/or reading skills in arithmetic paid off in terms of greater achievement, especially in the area of problem solving" [18] Earp's work was almost fifty years ago yet it still very timely.

Vocabulary instruction in mathematics just as in other disciplines holds some unique challenges. First, certain concepts in mathematics are embedded within other concepts to be defined and understood. Another aspect of mathematics vocabulary that holds potential difficulty for students is the complex overlap of this vocabulary with the vocabulary used in "ordinary" English. Shuard and Rothery [17] maintain that teachers need to explain to students that there are three categories of words used in mathematics: word that have the same meaning in Mathematical language and the ordinary spoken language words (native to that person); words that have meaning only in math; and the words that have different meanings in the other two contexts [16]. We must also remember that words can differ in meaning between languages such as sweet bread in the English language is a dish from the internal organs of beef while sweet bread in the Hispanic language is tasty yeast bread [26].

\section{Results}

Vygotsky has repeated over and over that children do not develop meaning for words on their own or 
independently of their world [27]. Words have a meaning which is derived from the endorsed discourse of use. It might be a social context or historical. The social world helps the child determine the direction needed for a word. Adults, on the other hand have a much more developed form of communication both verbally and written. This allows them to often predetermine the needed path for the development of generalization and finally reach a point to have a fully formed concept [28].

As you reflect on my example, please remember I am an Anglo female from a very isolated part of the US and have little contact with anyone who speaks anything other than Standard English. My example is if I were taught verbally, using a recording or a person, or even giving written/typed paper which happened to be in Russian, I am sure I could memorize that but until I knew it was The Lord's Prayer, I would only be making some sounds. Those sounds would have no meaning what so ever but after I knew I was actually saying The Lord's Pray, I would be able to mentally translate and put meaning to them.

Now let's go back to the teaching of mathematics vocabulary. If we say 'add' mental pictures of a symbol of an addition sign ( + ) comes into one's mind. If one really thinks about I, mathematics is like speaking two languages at one time. You have the verbal word and a symbol. If you are not a person who has English as your first language, you are first translating the verbal word back into your first language to retrieve the meaning and then a symbol pops into the vision. All this must take place in order for the person to have the 'full' cognition of that single word. This is a spin-off of the Vygotskian notion that of a mathematical sign is necessary for and a productive of mathematical meaning-making. Berger advocates that the functional use of a mathematical sign entails activities such as imitation, association, template-matching and manipulation.

\section{Conclusion}

Vocabulary is not something for tomorrow or a thing of the past. It is for now and if we as educator strive for the education of the future generations we must be open to what the research is trying to convey. In future works, researchers and I need to address specific activities to provide guides to help new educators. These activities will need to be in the formats of 'good' lessons where the new educator has everything at his/her fingertips. The activities will need to also include evaluation and assessment components as there will be no one in doubt if the action was successful or not. We can't leave this important aspect of education to chance.

\section{References}

[1] Braselton, S., \& Decker, B. C. (1994). Using graphic organizers to improve the reading of mathematics. The Reading Teacher, 48(3), 276-281.

[2] Lucas, C. A \& Goerss, B. L. (2007) Using a postgraphic organizer in the mathematics classroom. Journal of Reading Education. 32(2)26-30.

[3] Patton, B. (2016) Helping student master the math lingo of situational problems. (In review)

[4] Patton, B. S. (2010) Reading Left to Right: Not true for all math illustrations. Fourth International Ethnomathematics Conference, Towson. MA.

[5] Woodward, A. L., \& Hoyne, K. L. (1999). Infants' learning about words and sounds in relation to objects. Child Development, 70, 65-77.

[6] Woodward, A. L., \& Markman, E. M. (1998). Early word learning. In W. Damon, D. Kuhn, \& R. Siegler (Eds.), Handbook of child psychology, Volume 2: Cognition, perception and language (pp. 371-420). New York: John Wiley \& Sons.

[7] Holliday, W. G. (1991). Helping students learn effectively from science text. In C.M. Santa and D.E. Alvermanm (Eds.) Science learning: processes and applications (pp. 38-47). Newark, DE: International Reading Association.

[8] Patton, B. A. (2014) Analysis of released math tests for students in elementary grades. (In review)

[9]Carter, T. A. \& Dean, E. O (2006) Mathematics intervention for grades 5-11: Teaching mathematics, reading, or both? Reading Psychology 27:127-146.

[10] National Council of Teachers of Mathematics. (1989). Professional standards for teaching mathematics. Reston, VA: National Council of Teachers of Mathematics.

[11] National Council of Teachers of Mathematics. (1990). Professional standards for teaching mathematics. Reston, VA: National Council of Teachers of Mathematics

[12] National Council of Teachers of Mathematics. (1991). Professional standards for teaching mathematics. Reston, VA: National Council of Teachers of Mathematics.

[13] National Council of Teachers of Mathematics. (2000). Professional standards for teaching mathematics. Reston, VA: National Council of Teachers of Mathematics.

[14] National Research Council, Mathematical Sciences Education Board. (1989) Everybody counts: A report to the nation on the future of mathematics education. Washington DC: National Academy Press.

[15] National Research Council, Mathematical Sciences Education Board. (1990). Reshaping school mathematics: A philosophy and framework for curriculum. Washington DC: National Academy Press. 
[16] Linville, W. J. (1976). Syntax, vocabulary and the verbal arithmetic problem. School Science and Mathematics 76, 152-158.

[17] Shuard, H., \& Rothery, A. (Eds.). (1984). Children reading mathematics. Athenaeum Press: Newcastle upon Tyne, England.

[18] Earp, N. W. (1970). Observations on teaching reading in mathematics. Journal of Reading, 13, 529-33.

[19] Earp, N. W., \& Tanner, F.W. (1980). Mathematics and language. Arithmetic Teacher,28(4), 32-34.

[20] Pierce, M. E. \& Fantaine, L. M. (2009) Designing vocabulary instruction in mathematics. The Reading Teacher. 63(3) 239-243.

[21] California Department of Education: (2010) Released state test items. Retrieved from http://www.cde.ca.gov/ta/ tg/sr/css05rtq.asp (Access Date: 12 August, 2017)

[22] Massachusetts Department of Education: (2010) Released state test items. Retrieved from http://www.doe. mass.edu/mcas/2012/release/ (Access Date: 12 August, 2017)

[23] Ohio Department of Education: (2010 Released state test items. Retrieved from http://education.ohio.gov/Topic s/Testing/Testing-Materials/Released-Test-Materials-fromthe-Ohio-Graduati-1/Grade-4-Released-Tests-MaterialsOGT (Access Date: 12 August, 2017)

[24] Texas Department of Education: (2010) Released state test items. Retrieved from http://tea.texas.gov/student.assessment/released-tests/ (Access Date: 12 August, 2017)

[25]Virginia Department of Education: (2010) Released state test items. http://www.doe.virginia.gov/testing/sol/ released_tests/archive.shtml (Access Date: 12 August, 2017)

[26] Patton, B. A. (2012) The language of mathematics.Unpublished manuscript.

[27] Berger, M. (2004) The Functional use of a mathematical sign. Educational Studies in Mathematics, 55(1) 81-102.

[28] Vygotsky, 1. (1986) Thought and Language. A. Kozulin, (ed and trans.) MIT Press. Cambridge, MA. 